\title{
Metallothinein 1E Enhances Glioma Invasion through Modulation Matrix Metalloproteinases-2 and 9 in U87MG Mouse Brain Tumor Model
}

\author{
Hyuk Hur, M.D., ${ }^{1 *}$ Hyang-Hwa Ryu, Ph.D., ${ }^{2 *}$ Chun-Hao Li, M.D., ${ }^{2}$ In Young Kim, M.D., Ph.D., ${ }^{1}$ Woo-Youl Jang, M.D., ${ }^{1}$ Shin Jung, M.D., Ph.D. ${ }^{1,2}$ \\ Department of Neurosurgery, ${ }^{1}$ Brain Tumor Clinic and Gamma Knife Center and Brain Tumor Research Laboratory, ${ }^{2}$ and \\ Chonnam National University Research Institute of Medical Sciences, Chonnam National University Medical School and Hwasun Hospital, \\ Hwasun, Korea
}

Malignant glioma cells invading surrounding normal brain are inoperable and resistant to radio- and chemotherapy, and eventually lead to tumor regrowth. Identification of genes related to motility is important for understanding the molecular biological behavior of invasive gliomas. According to our previous studies, Metallothionein 1E (MT1E) was identified to enhance migration of human malignant glioma cells. The purpose of this study was to confirm that MT1E could modulate glioma invasion in vivo. Firstly we established 2 cell lines; MTS23, overexpressed by MT1E complementary DNA construct and pV12 as control. The expression of matrix metalloproteinases (MMP)-2, - 9 and a disintegrin and metalloproteinase 17 were increased in MTS23 compared with pV12. Furthermore it was confirmed that MT1E could modulate MMPs secretion and translocation of NFkB p50 and B-cell lymphoma-3 through small interfering ribonucleic acid knocked U87MG cells. Then MTS23 and pV12 were injected into intracranial region of 5 week old male nude mouse. After 4 weeks, for brain tissues of these two groups, histological analysis, and immunohistochemical stain of MMP-2, 9 and Nestin were performed. As results, the group injected with MTS23 showed irregular margin and tumor cells infiltrating the surrounding normal brain, while that of pV12 (control) had round and clear margin. And regrowth of tumor cells in MTS23 group was observed in another site apart from tumor cell inoculation. MT1E could enhance tumor proliferation and invasion of malignant glioma through regulation of activation and expression of MMPs.

Key Words : Metallothionein 1E $\cdot$ Malignant glioma $\cdot$ Invasion $\cdot$ Brain tumor model $\cdot$ MMP-2 $\cdot$ MMP-9.

\section{INTRODUCTION}

Malignant glioma is the most malignant form of primary brain tumors and constitutes approximately $25 \%$ of primary adult brain tumors ${ }^{14)}$. Despite modern diagnostics and treatments, the median survival time does not exceed 15 months. Because local invasion of malignant glioma is causative of recurrence and therapeutic failure, it is important to study the molecular basis of biological behavior of invasive tumor cells. In our previous study, we identified that Metallothionein $1 \mathrm{E}$ (MT1E) could modulate migration and invasion in human malignant glioma cells through in vitro experiments ${ }^{24)}$.

MT1E, a small metal binding protein, is cysteine rich and has a high affinity for heavy metal ions, such as zinc, cadmium, cop- per, mercury, and platinum. It plays the role of metal homeostasis, heavy metal detoxification, chemoresistance, and poor prognosis of some tumors ${ }^{23,25)}$. A striking feature of MT1E is that they can modulate the activities of zinc dependent proteins including enzymes and zinc-finger transcription factors, by the removal and transfer of zinc ${ }^{18)}$. We focused on these functions and studied nuclear factor $k \mathrm{~B}(\mathrm{NF} k \mathrm{~B})$ and matrix metalloproteinases (MMPs) associated with cell migration among zinc dependent factors.

$\mathrm{NF} k \mathrm{~B}$ is a zinc dependent transcription factor that is involved in cellular responses to stimuli such as stress, cytokines, free radicals, ultraviolet irradiation, etc. Roles in cancer regulate various genes that control cell proliferation and cell survival ${ }^{5)}$, and resistant to chemotherapeutic agents ${ }^{2,13)}$. For NFkB activation,

- Received : April 29, 2016 • Revised : July 20, 2016 •Accepted : July 21, 2016

*These authors equally contributed in this work.

- Address for reprints : Shin Jung, M.D., Ph.D.

Department of Neurosurgery, Chonnam National University Research Institute of Medical Sciences, Chonnam National University Medical School and Hwasun Hospital, 322 Seoyang-ro, Hwasun-eup, Hwasun 58128, Korea

Tel : +82-61-379-7666, Fax : +82-61-379-7673, E-mail : sjung@jnu.ac.kr

- This is an Open Access article distributed under the terms of the Creative Commons Attribution Non-Commercial License (http://creativecommons.org/licenses/by-nc/3.0) which permits unrestricted non-commercial use, distribution, and reproduction in any medium, provided the original work is properly cited. 
two main pathways exist in cells. One is the canonical pathway that is induced by most physiological NFkB stimuli and leads mainly to phosphorylation of NFkB inhibitor ( $\mathrm{IkBa}$ ) and nuclear translocation of mostly p65-containing heterodimers. Another is the noncanonical pathway that depends on $\mathrm{IkB}$ kinase a-mediated phosphorylation of p100 associated with p52-RelB complex and leads to partial processing of p100 and the generation of p52-RelB complexes. The released NFkB then enters the nucleus and activates the transcription of many different target genes $^{21)}$.

MMPs belong to a family of zinc-dependent endopeptidases that degrade the extracellular matrix. Especially, MMPs have well known effects on tumor proliferation and metastasis. They are synthesized in the latent form and secreted as proenzymes and require extracellular activation. The presence of a propeptide in the MMPs contains a cysteine residue, which forms the coordination between the cysteine thiol with the zinc atom in the catalytic domain, and prevents MMPs from being active ${ }^{22}$. Primary tumor cell invasion of the surrounding tissue is the first stage of a metastasis cascade, and many factors, such as MMPs, are associated with this stage $\mathrm{e}^{20)}$.

In the present study, we investigated that MT1E could actually enhance glioma invasion in vivo brain tumor model and identified the association NFkB and MMPs in glioma invasion.

\section{MATERIALS AND METHODS}

\section{Cell culture}

Human malignant glioma cell line U87MG and U343MG (Korean cell line bank, Seoul, Korea) was routinely maintained in Dulbecco's modified Eagle's medium (DMEM, GibcoBRL, Gaithersburg, MD, USA) supplemented with $10 \%$ fetal bovine serum (FBS, GibcoBRL, Gaithersburg, $\mathrm{MD}, \mathrm{USA}$ ) at $37^{\circ} \mathrm{C}$ in a humidified $95 \%$ air/ $5 \% \mathrm{CO}_{2}$ atmosphere.

\section{siRNA oligonucleotide transfection}

A small interfering RNA oligonucleotide was used for MT1E knockdown. The synthesized MT1E siRNA (5'-CCUGACUGC UUGUUCGUCU-3') and scrambled ribonucleic acid (negative control) were purchased from Bioneer (Daejeon, Korea). Approximately $2 \times 10^{5}$ cells were seeded on a plate and transfected with the siRNA oligonucleotide using Lipofectamine ${ }^{\mathrm{TM}}$ RNAiMAX (Invitrogen, Carlsbad, CA, USA), according to the manufacturer's instructions. MT1E knockdown was confirmed by Western blotting.

\section{Stable transfection}

\section{Preparation of metallothionein $1 \mathrm{E}$ construct}

The complete coding region of the human MT complementary (cDNA) was amplified from U87MG cDNA by polymerase chain reaction (PCR) with synthetic primers. The polymerase chain reaction primers were designed as follows. MT-Sense :
5'-CGGGATCCATGGACCCCAAC TGCTCTT-3', 5'-GCTC TAGAGCTCAGGCACAGCAG CTGCACT-3'. MT-anti sense : 5'-GCTCTAGAGCATGGACCCCAACTGCTCTT-3', 5'-CG GGATCCTCAGGCACAGCAGCTGCACT-3' The amplified cDNA was sequenced and directly subcloned into the pcDNA3.1 (+) vector (Invitrogen, San Diego, CA, USA) between the $\mathrm{BamHI}$ and $\mathrm{XbaI}$ sites, which is contained within the CMV promoter and the neomycin resistance gene. The resulting vectors were designated as pcDNA3.1-MT-S, pcDNA3.1-MT-AS.

\section{Transfection}

For ex vivo study, U343-MT-S and U87-MT-AS designated in our previous experiment were used ${ }^{24)}$. In brief, U343-MT-S and U87-MT-AS were respectively transfected with sense MT1E cDNA plasmid (pcDNA3.1-MT-S) in U343MG and antisense MT1E cDNA plasmid (pcDNA3.1-MT-AS) in U87MG. And for in vivo study MTS23 cell line was newly established in U87MG as follow. The optimal cell density for transfection is normally between 50 and $80 \%$ confluency for adherent cells. Empty vector and pcDNA3.1-MT-S were respectively transfected into U87MG using Lipofectamine 2000 (Invitrogen, San Diego, CA, USA). Cells in serum-free DMEM were mixed with 1 $\mu \mathrm{g}$ of plasmid DNA and $10 \mu \mathrm{L}$ of Lipofectamine 2000/serumfree media according to the manufacturer's protocol. After incubation at $37^{\circ} \mathrm{C}\left(5 \% \mathrm{CO}_{2}\right)$ for $5 \mathrm{~h}$, the transfection mixture was replaced with DMEM supplemented with 10\% FBS. After $24 \mathrm{~h}$ incubation, the medium was replaced with DMEM containing $10 \% \mathrm{FBS}$ and $500 \mathrm{ug} / \mathrm{mL}$ G418. The transfectants were designated as pV12 (control) and MTS23, respectively.

\section{Preparation of total protein and conditioned media}

For the preparation of total protein, cells were lysed in a protein extraction buffer [50 mM Tris ( $\mathrm{pH} 8.0$ ), $5 \mathrm{mM}$ ethylenediaminetetraacetic acid, $150 \mathrm{mM}$ sodium chloride, $0.5 \%$ deoxycholic acid, $0.1 \%$ sodium dodecyl sulfate, $1 \%$ NP- $40,1 \mathrm{mM}$ phenylmethane sulfonyl fluoride, and $1 \mathrm{mg} / \mathrm{mL}$ protease inhibitor cocktail]. For the preparation of conditioned media, cells were grown in $60-\mathrm{mm}$ plates until they were subconfluent, and then $1 \mathrm{~mL}$ of serum-free medium was added to each plate. After incubation for $48 \mathrm{hr}$, the conditioned media were clarified by centrifugation. The protein concentration was determined using the Bio-Rad protein assay kit (Bio-Rad, Hercules, CA, USA).

\section{Gelatin zymography}

Gelatin zymography was carried out as described previous$\mathrm{ly}^{15)}$. Briefly, proteins $(20 \mu \mathrm{g})$ in conditioned media were mixed with sample buffer ( $50 \mathrm{mM}$ Tris- $\mathrm{HCl}, 2 \%$ SDS, $0.1 \%$ bromophenol blue, and $10 \%$ glycerol before electrophoresis). Aliquots were electrophoresed on $8 \%$ SDS-polyacrylamide gels containing 1 $\mathrm{mg} / \mathrm{mL}$ type A gelatin (Sigma-Aldrich, St. Louis, MO, USA). Each gel was washed three times for $30 \mathrm{~min}$ in $2.5 \%$ Triton X-100 and then incubated for $20 \mathrm{~h}$ at $37^{\circ} \mathrm{C}$ in incubation buffer [ $50 \mathrm{mM}$ Tris- $\mathrm{HCl}$ (pH 7.5), $10 \mathrm{mM} \mathrm{CaCl}_{2}$, and $200 \mathrm{mM} \mathrm{NaCl}$. The gels 
were stained with Coomassie Brilliant Blue R-250 (0.2\% Coomassie Brilliant Blue R-250, 20\% methanol, 10\% acetic acid in water) and then destained in 20\% methanol and $10 \%$ acetic acid in water.

\section{Western blot}

A total of $20 \mu \mathrm{g}$ of whole cell lysates were separated by $15 \%$ SDS-PAGE and transferred to a polyvinylidene difluoride membrane (Pall Corporation, Pensacola, FL, USA). The membrane was then incubated for $2 \mathrm{hrs}$ at room temperature in TBS-T solution [10 mM Tris-Cl (pH8.0), $150 \mathrm{mM} \mathrm{NaCl}$, and 0.05\% Tween 20] supplemented with 5\% non-fat dry milk and probed overnight at $4^{\circ} \mathrm{C}$ with anti-MT1E (Sigma-Aldrich, Saint Louis, MD, USA), anti-MMP2, MMP9 (Abcam, Cambridge, UK), anti-Actin, NFkB p50, Lamin B and p-ikB (Santa Cruz Biotechnology, Santa Cruz, CA, USA) and anti-Nestin (BD Pharmingen, San Diego, CA, USA). The bound antibodies were visualized with the appropriate horseradish peroxidase-conjugated secondary antibody (Abfrontier, Seoul, Korea) conjugated with horseradish peroxidase using enhanced chemiluminescence reagents (ECL, Millipore, Billerica, MA, USA).

\section{Brain slice invasion study of transfectants}

In an attempt to recapitulate the matrix macromolecule representation normally encountered by infiltrating glioblastoma cells, we performed organotypic cultures, as previously described by Jung et al. ${ }^{10,11)}$. By using the DiI (1,1'-Dioctadecyl-3,3,3,3'tetramethylindocarbocyanine perchlorate, 97\%, Aldrich chem.) stained cells, it was possible to evaluate the invasiveness in a brain slice model. Briefly, rat brain was cut into 1 -mm-thick, $8 \times 8$ $\mathrm{mm}^{2}$ slices using a brain matrix (Harvard instruments, Boston, MA, USA) and placed onto the upper chamber of Transwell culture dishes $(0.4 \mu \mathrm{m}$ in pore size, Coring Incorporated-Life Scences, Lowell, MA, USA). The brain slices were incubated in medium containing DMEM including $10 \%$ FBS. Five $\times 10^{5}$ tumor cells were placed on a central hole of the brain slice and incubated for 14 days.

\section{In vivo studies}

Five- to six-week old male BALB/c athymic nu-/nu- mice (body weight, 20-30 g) were purchased from the Orient Co. (Seongnam, Korea). They were housed in groups of three or four under standard conditions at a temperature of $22^{\circ} \mathrm{C}$ and a 12-h light/ 12-h dark cycle. The mice had free access to standard food pellets and tap water. The mice were anesthetized with isoflurane $(2 \%)$, and a mixture of ketamine $(200 \mathrm{mg} / \mathrm{kg})$ and xylazine $(10$ $\mathrm{mg} / \mathrm{kg}$ ). $5 \times 10^{5}$ of $\mathrm{pV} 12$ and MTS23 cell lines were suspended in free-DMEM and injected stereotactically into the right striatum, respectively. After 3 weeks, all mice inoculated pV12 and MTS 23 cell lines were sacrificed. Animal care, experiments, and euthanasia were performed in accordance with the protocols approved by the Chonnam National University Animal Research Committee (Gwangju, Korea).

\section{Histopathology}

All mice were anesthetized and perfused transcardially with $4 \%$ zinc salt-based fixation-containing $36.7 \mathrm{mM} \mathrm{ZnCl}_{2}, 27.3$ $\mathrm{mM} \mathrm{ZnAc} \cdot 2 \mathrm{H}_{2} \mathrm{O}$, and $0.63 \mathrm{mM} \mathrm{CaAc}_{2}$ in $0.1 \mathrm{M}$ Tris, $\mathrm{pH}$ 7.4. The brain tumor was removed, fixed in the same solution for 36-38 $\mathrm{h}$ at room temperature, and then dehydrated for paraffin embedding. The tumors were blocked in cross-section and processed for paraffin embedding.

Three $\mu \mathrm{m}$-thick consecutive sections were cut from the recipient blocks and placed on poly-L-lysine-coated slides for immunohistochemistry. Representative sections were stained with $\mathrm{H} \& \mathrm{E}$. Heat-induced epitope retrieval was carried out for 10 min at $100^{\circ} \mathrm{C}$ in a pressure cooker in $10 \mathrm{mM}$ citrate buffer, $\mathrm{pH}$ 9.0 (DAKO, Carpinteria, CA, USA). Endogenous peroxidase activity was blocked by incubating the samples in phosphate buffer saline (PBS) containing $3 \% \mathrm{H}_{2} \mathrm{O}_{2}$, and the non-specific binding sites were blocked with $3 \%$ bovine albumin (Sigma-Aldrich, Saint Louis, MO, USA) in PBS for $20 \mathrm{~min}$ at room temperature. The following primary monoclonal antibodies were added : matrix metalloproteinases-2 and MMP-9 (1 : 8000; Abcam, Cambridge, UK) and Nestin (1:4000, BD Biosciences PharMingen, Burlingame, CA, USA). A biotin-labeled secondary antibody (Vector Laboratory, USA) was then added, and the samples were incubated at room temperature for $1 \mathrm{~h}$. A streptavidin-horseradish peroxidase detection system (Vector Laboratory, Burlingame, CA, USA) was followed by $20 \mathrm{~min}$ incubation at room temperature. The tissue sections were ready for the chromogen reaction with diaminobenzidine. Counterstaining was performed with Hematoxylin.

\section{RESULTS}

\section{MT1E enhanced invasion of malignant glioma cell lines in ex vivo study}

According to our previous in vitro studies, we identified MT1E could induce migration and proliferation of malignant glioma cells $^{24)}$. Before in vivo experiment, we desired to confirm whether MT1E could also enhanced invasion of malignant glioma through brain extracellular matrix and organotypic culture was performed $^{10,12)}$. U343-MT-S, overexpressing MT1E, migrated widely throughout the surrounding normal brain, compared with control cells. U87-MT-AS showed less invasiveness, compared with parental cells (Fig. 1).

\section{Endogenous MT1E content}

To assess the effect of MT1E on glioma invasion according to in vivo study, 'MTS23' continuously overexpressing MT1E was established in U87MG. As shown Fig. 2A, MT1E was highly expressed in MTS23 cells, compared with pV12 (control).

\section{MT1E overexpression modulates MMP-2, 9 and ADAM17 in U87MG}

On the basis of our previous study, we examined whether 


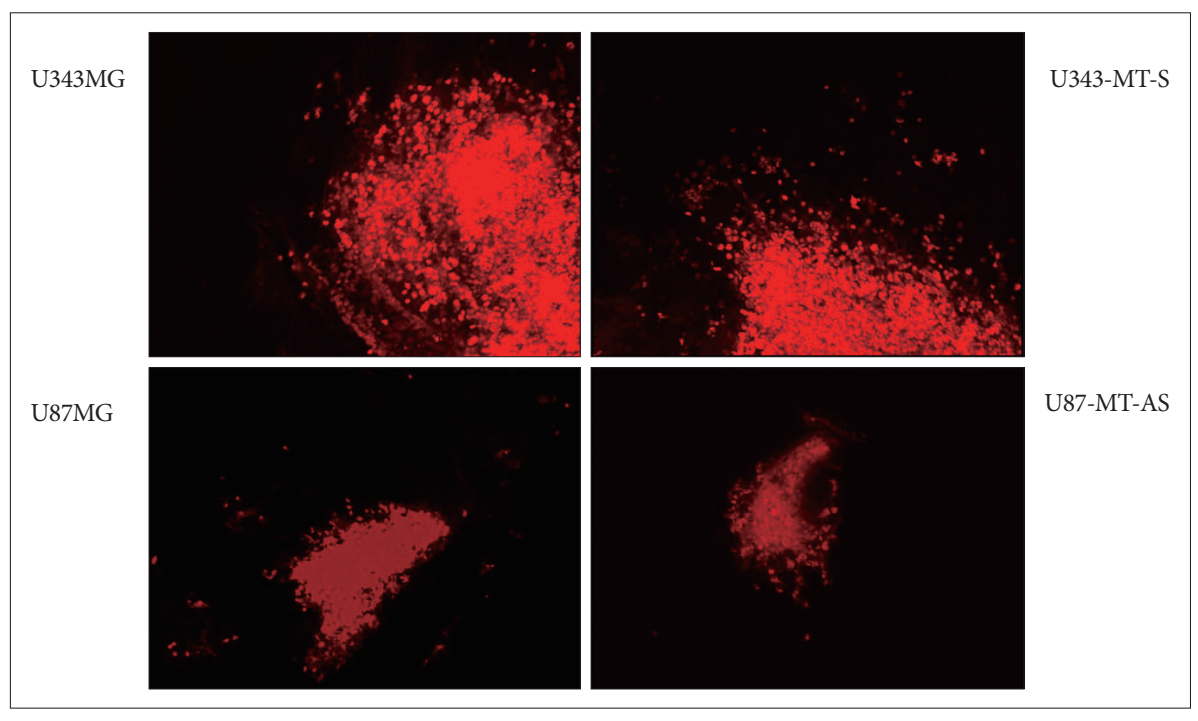

Fig. 1. The effect of MT1E on tumor cell invasion using organotypic culture. MT1E could enhance migration and invasion of human malignant glioma cells ex vivo. MT1E : metallothionein $1 \mathrm{E}$.

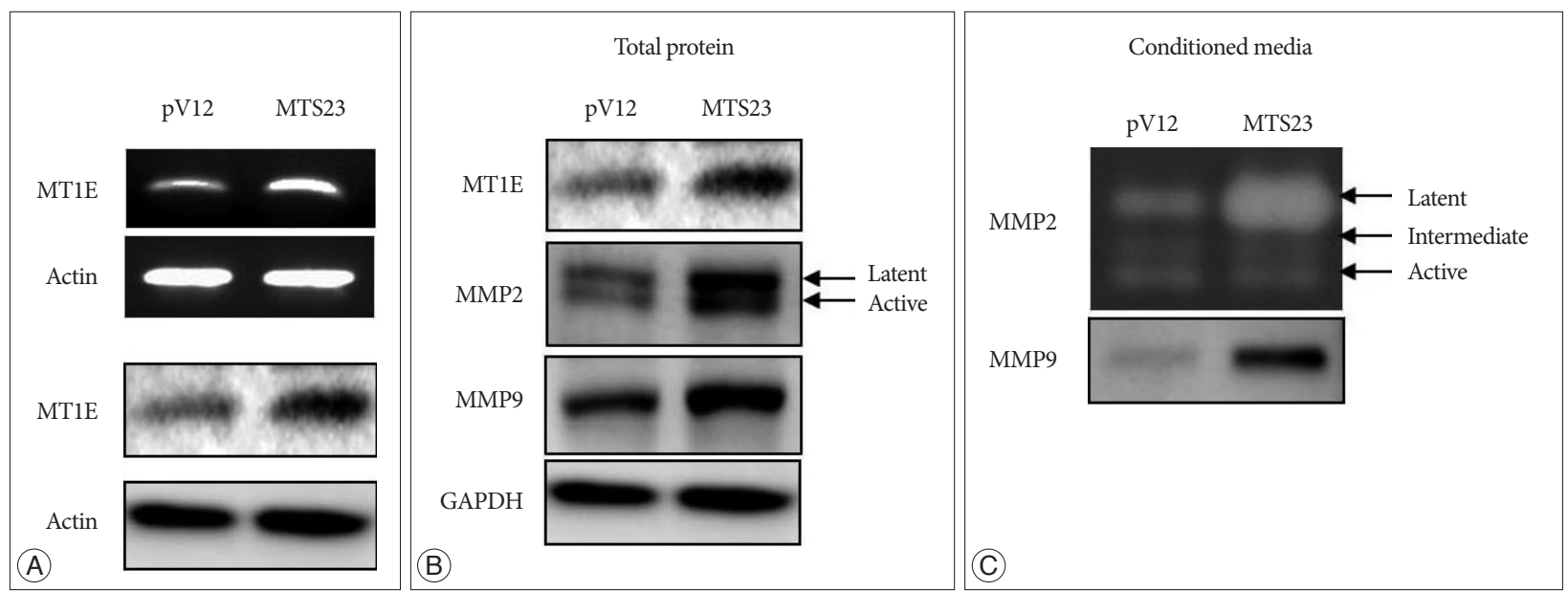

Fig. 2. MT1E modulates MMP-2, 9 and ADAM17 in U87MG. A : The stable cell line overexpressing MT1E ('MTS23') was established and endogenous MT1E was detected by RT-PCR (upper) and Western blot (lower). 'MTS23'; U87MG cells transfected with sense MT1E plasmid, 'pV12' (control); U87MG cells transfected with empty vector. B : Western blot in cell lysate. C : Upper; Gelatin zymography, lower : Western blot in supernatant. MT1E : metallothionein $1 \mathrm{E}, \mathrm{MMP}$ : metalloproteinases, ADAM : a disintegrin and metalloproteinase, GAPDH : glyceraldehyde 3-phosphoate dehydrogenase.

MT1E modulates the expression of MMP-2, 9 and a disintegrin and metalloproteinase (ADAM) 17, and the activities of MMP2, 9. The expression of MMP-2, 9 and ADAM17 was increased in MTS23 cells overexpressing MT1E, compared with control (Fig. 2B). In general, zymography is a method for detection of MMP-2 and -9 activities, but we could not detected MMP-9 activity in U87MG according to these method. So secreted MMP-9 was detected by western blot. As results, the activity of MMP-2 and the expression of secreted MMP-9 were significantly increased in MTS23, compared with control (Fig. 2C).

For MT1E knockdown cell, NFkB p50 and B-cell lymphoma-3 (Bcl-3) expression was decreased in nuclear fraction but increased in cytosol fraction (Fig. 3A), and p-ikB expression was decreased (Fig. 3B), compared with control. The expression of MMP-1, 2, 9 and 13 in conditioned media were decreased of MT1E knockdown cell compared with control (Fig. 3C).

\section{MT1E enhanced tumor invasion in mouse brain tumor models}

We established brain tumor model in order to confirm whether MT1E actually modulated tumor cell invasiveness in vivo environment. Brain tumors of the group inoculating pV12 (control group) had round and clear margin (Fig. 4A), while that of MTS23 (MTS group) showed irregular margin and tumor cells infiltrating the surrounding normal brain (Fig. 4B). And regrowth of tumor cells in MTS23 group was observed in another site apart from tumor cell inoculation (Fig. 4C). Tumor volume of MTS23 group was larger than that of pV12.

\section{MT1E was associated with shorter survival in mouse brain tumor models}

We had detected survival rate between control group $(\mathrm{n}=10)$ and MTS23 group $(n=10)$ during 70 days in order to confirm whether MT1E modulated tumor survival in vivo environment. 
As shown Fig. 5, the survival rate of MTS23 group was much shorter than that of $\mathrm{pV} 12$ control $(p=0.048)$.

\section{MT1E modulated secretion of MMPs through NFkB p50 and Bcl-3}

In the previous study, we mentioned the possibility of associa- tion between MT1E and MMPs and desired to confirm whether MT1E could modulate MMPs and NFkB in U87MG malignant glioma cell. In brain tumors of the MTS23 group, MMP-2 and -9 were highly expressed on marginal region and tumor cells infiltrated the normal brain, while those in the control group were expressed on tumor region. Tumor cells were identified by im-
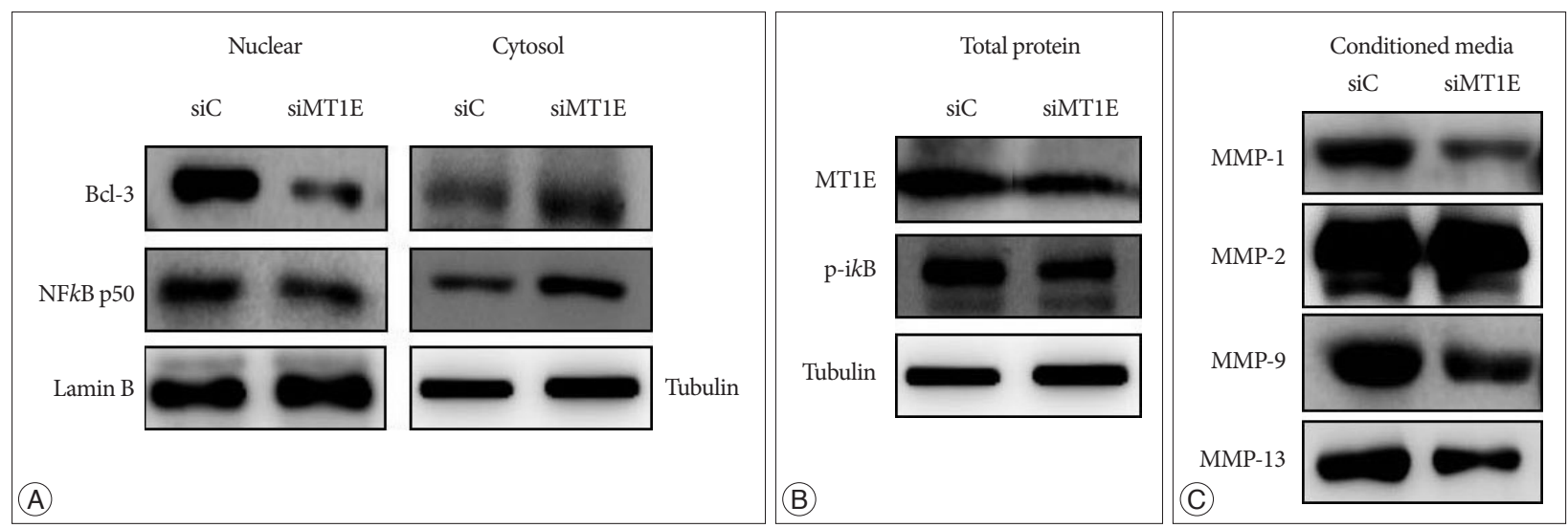

Fig. 3. MT1E modulated secretion of MMPs through NFkB p50 and Bcl-3. The expression of these proteins was detected by Western blotting. (A) Western blot in nuclear, cytosol fraction and (B) total cell lysate. (C) Western blot in conditioned media. 'siC'; scramble RNA transfected U87MG, 'siMT1E'; siRNA for MT1E transfected U87MG. MT1E : metallothionein 1E, MMP : metalloproteinases, Bcl-3 : B-cell lymphoma-3, RNA : ribonucleic acid.
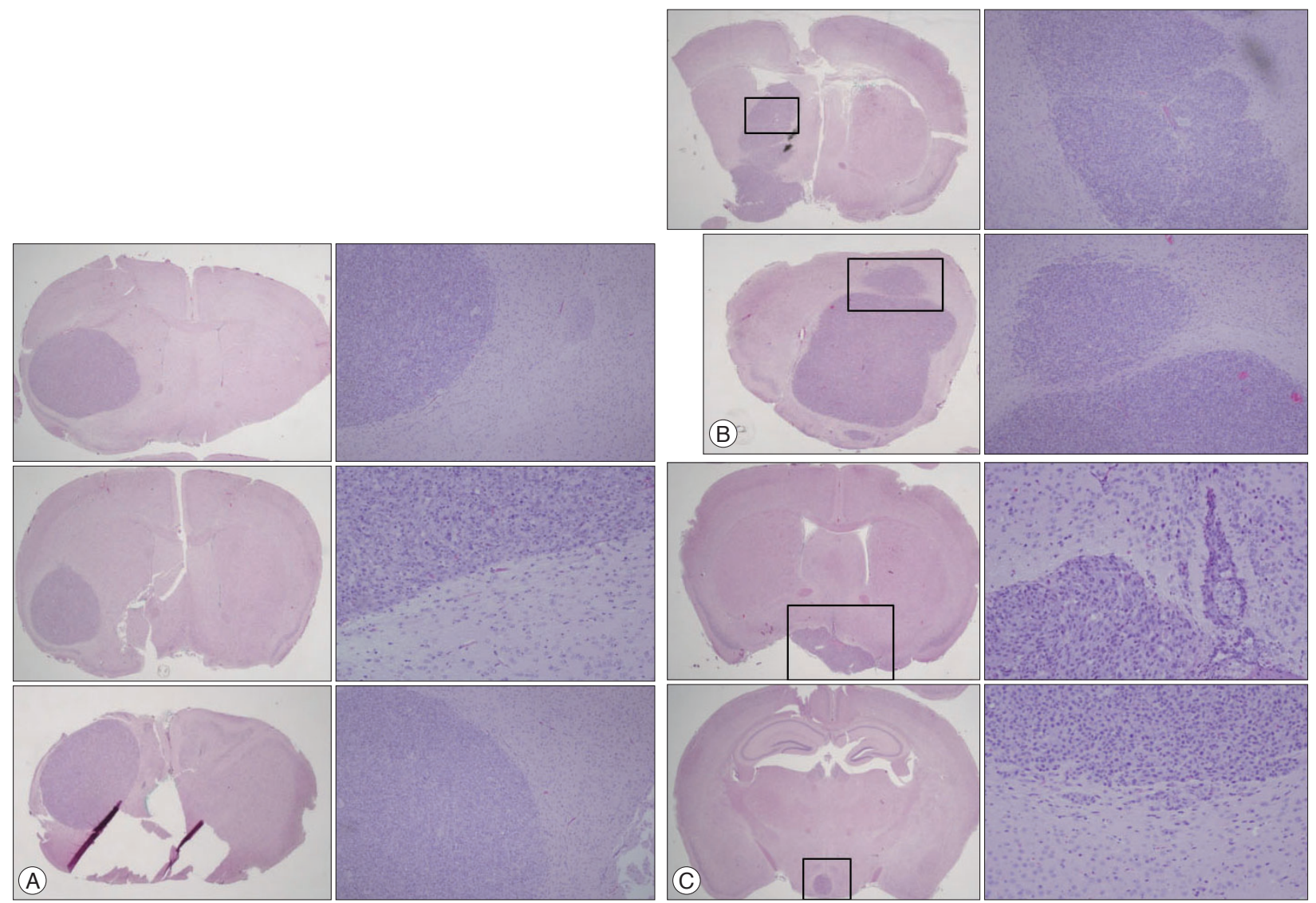

Fig. 4. Brain tumor growth patterns of 2 groups inoculating pV12 cells and MTS23. A : pV12 implanted group. B and C : MTS23 implanted group. Tumors of MTS inoculated group showed irregular margin and tumor cells infiltrating the surrounding normal brain (B), while that of pV12 (control) had round and clear margin (A). And regrowth of tumor cells in MTS23 group was observed in another site apart from tumor cell inoculation (C) but in pV12 group was nowhere to be found. 
munohistochemistry for Nestin (Fig. 6).

\section{DISCUSSION}

Based on our previous study, we investigated whether MT1E actually modulates malignant glioma invasion ex vivo and in vivo. For in vivo study, MTS23 continuously overexpressing MT1E and pV12 as control were established in U87MG human malignant glioma cell line and inoculated to nude mouse brain.

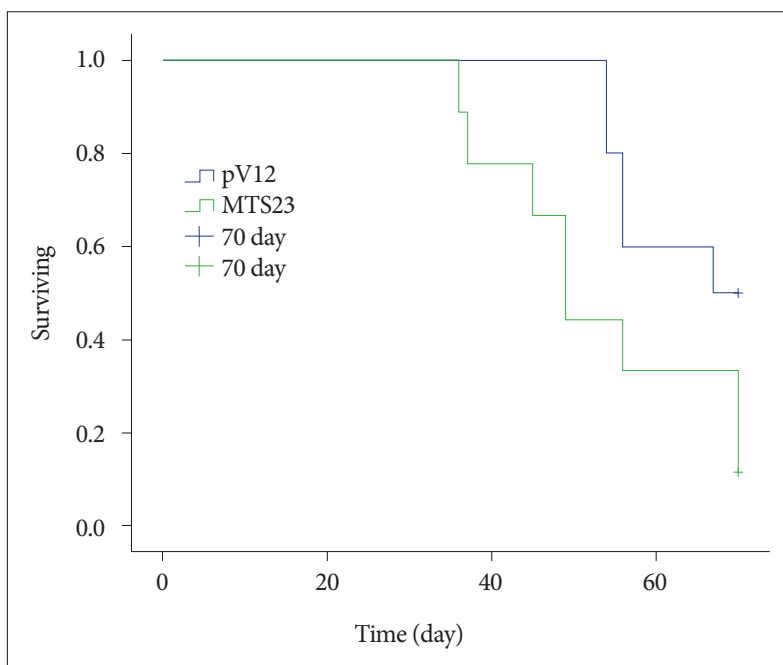

Fig. 5. The comparison of the survival rate between 2 groups inoculating pV12 cells and MTS23. The survival rate had detected during 70 days after inoculating tumor cells and was calculated by means of KaplanMeier survival analysis in orthotopic mouse brain tumor models. Mice transplanted with MTS23 cells showed a longer survival than mice transplanted with $\mathrm{pV} 12$ cells (70 days, $p<0.048)$.
MTS23 group showed irregular margin and tumor cells that had infiltrated the surrounding normal brain. And tumor size was also significantly higher than the control group. Furthermore the survival rate of the mice in MTS23 group was significantly reduced, compared with the mice in the control group.

MT1E is well known to regulate essential metals such as Zn, $\mathrm{Cu} .10 \%$ of mammalian proteasome consist of zinc binding proteins that are associated with cell signaling, gene expression, membrane structure stability, function, cell respiration, etc ${ }^{8}$. These functions of MT1E may be associated with rapid tumor growth. There are some reports that MT is related to tumor grade, malignancy, and prognosis in certain tumors such as colon can$\operatorname{cer}^{3)}$, lung cancer ${ }^{26)}$, brain tumors etc ${ }^{7)}$, and breast cancer ${ }^{9)}$. Zinc is also essential for endopeptidase proteolytic capacity to degrade the extracellular matrix, compounds with zinc-chelating groups ${ }^{8)}$. We focused on these functions of MT1E, and identified whether MT1E could regulate the expression of NFkB p50 and Bcl-3 transcription factors and MMPs for enhancing glioma invasion through in vitro and in vivo studies.

MMPs are a family of $\mathrm{Zn}^{2+}$-dependent endopeptidases that are capable of degrading the components of extracellular matrix. They have been regarded as critical factors promoting tumor cells invasion. The catalytic domain of all MMPs contain a $\mathrm{Zn}^{2+}$ ion coordinated by a tris (histidine) motif; the $\mathrm{Zn}^{2+}$ ion is critical for both substrate binding and cleavage ${ }^{1)}$. This Cys- $\mathrm{Zn}^{2+}$ coordination keeps proMMPs inactive by preventing a water molecule essential for catalysis from binding to the zinc atom. The enzymes are activated when a prosegment peptide is pulled away from the active center by breaking the cysteine-zinc contact and cleaved from the proenzyme. The zinc binding motif and the

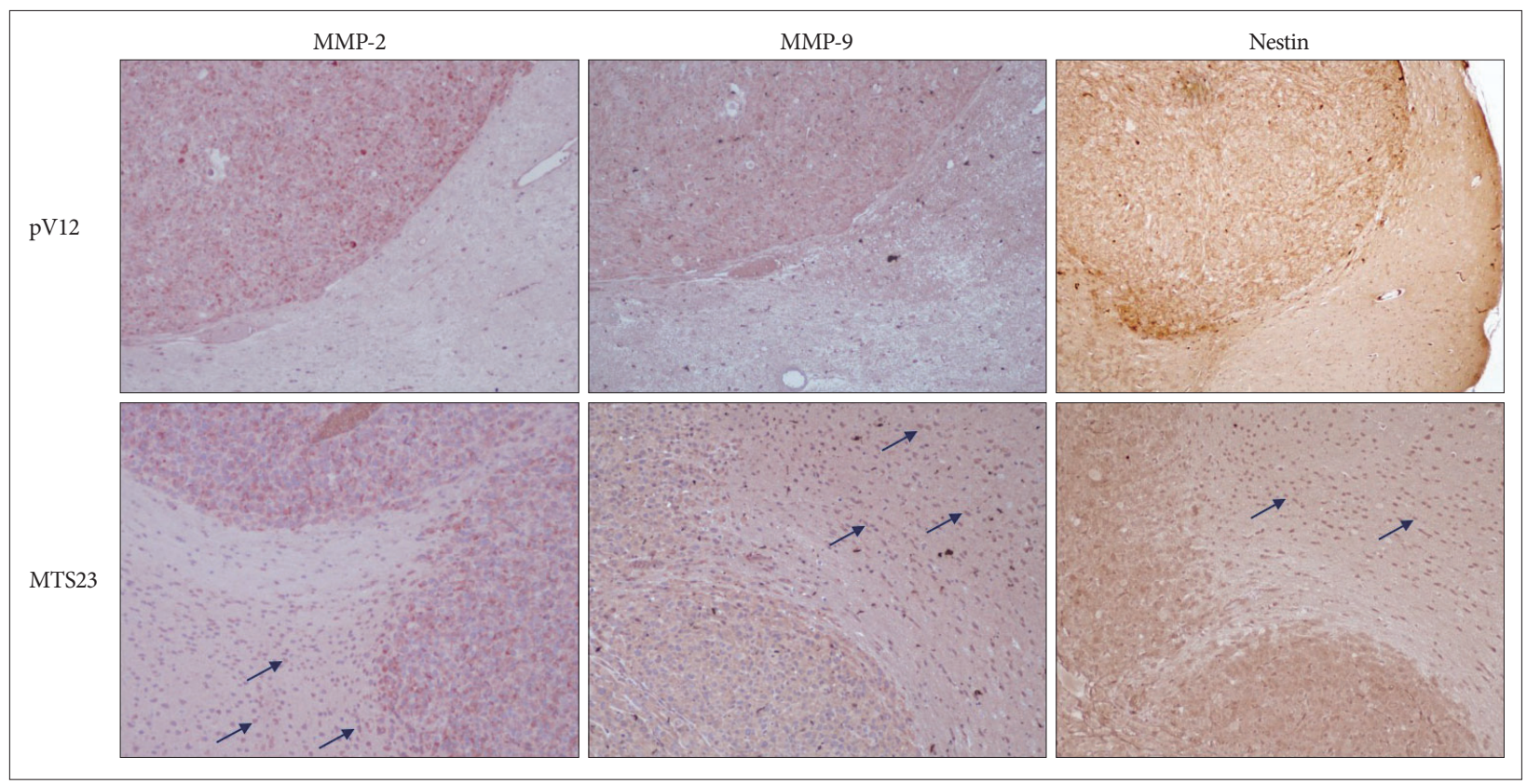

Fig. 6. MMP-2 and -9 were highly expressed on marginal region and tumor cells infiltrated the normal brain (arrow) in MTS23 group, while those in the control group were expressed on tumor, but not on normal region. And tumor cells were identified by immunohistochemistry for Nestin. MMP : metalloproteinases. 
Met-turn are also conserved in members of the ADAM fami$1 y^{16,19)}$. Among them, ADAM17 has been reported to be associated with migration and invasion of various tumor cell such as glioblastoma $^{4)}$, non-small cell lung cancer ${ }^{17)}$ and breast cancer ${ }^{6)}$.

MMPs has proteolytic activity after secretion in extracellular matrix. So it examined the change of the expression level of MMPs in both total cell lysates and conditioned media. As expected, the expression of MMP-1, 2, 9 and 13 secreted in conditioned media were decreased in transiently MT1E knockdown cells, compared with control. Reversely, in MTS23 cells continuously overexpressing MT1E, the expression of MMP-2, 9 and ADAM17 was increased and the activation of MMP-2 and 9 in conditioned media were significantly increased, compared with pV12 cells (control). Furthermore, MMP-2 and 9 were highly expressed in cells infiltrated the normal brain of group inoculating MTS cells in vivo.

$\mathrm{NFkB}$, also a zinc-dependent transcription factor, plays a pivotal role in a diverse array of cellular activities and gene activations (30). There are strong pathophysiologic functional similarities between MT and NFkB. Our previous study showed that $\mathrm{MT} 1 \mathrm{E}$ regulated $\mathrm{NF} k \mathrm{~B}$ p 50 and Bcl-3 transcription factors, and this was confirmed in U87MG knock-downed MT1E using siRNA technique. The expression of $\mathrm{p}-\mathrm{i} k \mathrm{~B}$ was decreased and translocation of $\mathrm{Bcl}-3$ and NFkB p50 from cytoplasm to nuclear was also decreased compared with the control cells.

\section{CONCLUSION}

In the present study, we confirmed that MT1E could enhance the invasion and proliferation of malignant glioma cell and induced expression of MMP-2 and 9 in mouse brain tumor model. And MMPs secretion and NFkB/p50 expression were also changed by MT1E. Despite the fact that the direct relation between MMPs and NFkB/p50 was not identified, on the basis of our results and reports, we may be able to present two mechanisms. One is that MT1E may regulate MMPs activation by regulating $\mathrm{Zn}$ contained in MMPs structure, such as a $\mathrm{Zn}$ donor or recipient. The other is that MT1E may induce the activity of NFkB p50/Bcl-3, following MMPs activities in malignant glioma cell lines. Finally, this series of events enhances the invasion of malignant glioma.

\section{- Acknowledgements}

This study was supported by a grant (HCRI15008-1) Chonnam National University Hospital Biomedical Research Institute.

\section{References}

1. Agrawal A, Romero-Perez D, Jacobsen JA, Villarreal FJ, Cohen SM : Zinc-binding groups modulate selective inhibition of MMPs. ChemMedChem 3 : 812-820, 2008

2. Andela VB, Gordon AH, Zotalis G, Rosier RN, Goater JJ, Lewis GD, et al. : NFkappaB : a pivotal transcription factor in prostate cancer metastasis to bone. Clin Orthop Relat Res (415 Suppl) : S75-S85, 2003

3. Arriaga JM, Levy EM, Bravo AI, Bayo SM, Amat M, Aris M, et al. :
Metallothionein expression in colorectal cancer : relevance of different isoforms for tumor progression and patient survival. Hum Pathol 43 : 197-208, 2012

4. Chen X, Chen L, Chen J, Hu W, Gao H, Xie B, et al. : ADAM17 promotes U87 glioblastoma stem cell migration and invasion. Brain Res 1538 : 151-158, 2013

5. Escárcega RO, Fuentes-Alexandro S, García-Carrasco M, Gatica A, Zamora A : The transcription factor nuclear factor-kappa B and cancer. Clin Oncol (R Coll Radiol) 19: 154-161, 2007

6. Giricz O, Calvo V, Peterson EA, Abouzeid CM, Kenny PA : TACE-dependent TGFa shedding drives triple-negative breast cancer cell invasion. Int J Cancer 133 : 2587-2595, 2013

7. Hiura T, Khalid H, Yamashita H, Tokunaga Y, Yasunaga A, Shibata S : Immunohistochemical analysis of metallothionein in astrocytic tumors in relation to tumor grade, proliferative potential, and survival. Cancer 83 : 2361-2369, 1998

8. Huang ST, Yang RC, Wu HT, Wang CN, Pang JH : Zinc-chelation contributes to the anti-angiogenic effect of ellagic acid on inhibiting MMP2 activity, cell migration and tube formation. PLoS One 6 : e18986, 2011

9. Jin R, Bay BH, Chow VT, Tan PH : Metallothionein 1F mRNA expression correlates with histological grade in breast carcinoma. Breast Cancer Res Treat 66 : 265-272, 2001

10. Jung S, Ackerley C, Ivanchuk S, Mondal S, Becker LE, Rutka JT : Tracking the invasiveness of human astrocytoma cells by using green fluorescent protein in an organotypical brain slice model. J Neurosurg 94: 80-89, 2001

11. Jung S, Hinek A, Tsugu A, Hubbard SL, Ackerley C, Becker LE, et al. : Astrocytoma cell interaction with elastin substrates : implications for astrocytoma invasive potential. Glia 25 : 179-189, 1999

12. Jung TY, Jung S, Ryu HH, Jeong YI, Jin YH, Jin SG, et al. : Role of galectin-1 in migration and invasion of human glioblastoma multiforme cell lines. J Neurosurg 109 : 273-284, 2008

13. Karin M, Cao Y, Greten FR, Li ZW : NF-kappaB in cancer : from innocent bystander to major culprit. Nat Rev Cancer 2 : 301-310, 2002

14. Kim JE, Paek SH, Kim DG, Chung HT, Kim YY, Jung HW : The combined effect of gamma knife irradiation and p53 gene transfection in human malignant glioma cell lines. J Korean Neurosurg Soc 37 : 48-53, 2005

15. Kim YS, Jeong YI, Jin SG, Pei J, Wen M, Kim IY, et al. : Release of tissue inhibitor of metalloproteinase-2 from alginate microcapsule encapsulating genetically engineered cells. Int J Nanomedicine 8 : 4351-4359, 2013

16. Lokeshwar BL, Selzer MG, Block NL, Gunja-Smith Z : Secretion of matrix metalloproteinases and their inhibitors (tissue inhibitor of metalloproteinases) by human prostate in explant cultures : reduced tissue inhibitor of metalloproteinase secretion by malignant tissues. Cancer Res 53 : 4493-4498, 1993

17. Lv X, Li Y, Qian M, Ma C, Jing H, Wen Z, et al. : ADAM17 silencing suppresses the migration and invasion of non-small cell lung cancer. Mol Med Rep 9 : 1935-1940, 2014

18. Maret W, Jacob C, Vallee BL, Fischer EH : Inhibitory sites in enzymes : zinc removal and reactivation by thionein. Proc Natl Acad Sci U S A 96 : 1936-1940, 1999

19. Nagase H, Visse R, Murphy G : Structure and function of matrix metalloproteinases and TIMPs. Cardiovasc Res 69: 562-573, 2006

20. Nakajima M, Chop AM : Tumor invasion and extracellular matrix degradative enzymes : regulation of activity by organ factors. Semin Cancer Biol 2 : 115-127, 1991

21. Oeckinghaus A, Hayden MS, Ghosh S : Crosstalk in NF- $\kappa B$ signaling pathways. Nat Immunol $12: 695-708,2011$

22. Parks WC, Wilson CL, López-Boado YS : Matrix metalloproteinases as modulators of inflammation and innate immunity. Nat Rev Immunol 4 : 617-629, 2004

23. Roesijadi G : Metal transfer as a mechanism for metallothionein-medi- 
ated metal detoxification. Cell Mol Biol (Noisy-le-grand) 46 : 393-405, 2000

24. Ryu HH, Jung S, Jung TY, Moon KS, Kim IY, Jeong YI, et al. : Role of metallothionein $1 \mathrm{E}$ in the migration and invasion of human glioma cell lines. Int J Oncol 41 : 1305-1313, 2012

25. Satoh M, Cherian MG, Imura N, Shimizu H : Modulation of resistance to anticancer drugs by inhibition of metallothionein synthesis. Cancer Res 54: 5255-5257, 1994

26. Werynska B, Pula B, Muszczynska-Bernhard B, Piotrowska A, Jethon A, Podhorska-Okolow M, et al. : Correlation between expression of metallothionein and expression of Ki-67 and MCM-2 proliferation markers in non-small cell lung cancer. Anticancer Res $31: 2833-2839,2011$ 